\title{
Importance of Local Structural Variations on Recrystallization
}

Juul Jensen, Dorte; Lin, Fengxiang; Zhang, Yubin; Zhang, Y.H.

Published in:

Materials Science Forum

Link to article, DOI:

10.4028/www.scientific.net/MSF.753.37

Publication date:

2013

Link back to DTU Orbit

Citation (APA):

Juul Jensen, D., Lin, F., Zhang, Y., \& Zhang, Y. H. (2013). Importance of Local Structural Variations on

Recrystallization. Materials Science Forum, 753, 37-41. https://doi.org/10.4028/www.scientific.net/MSF.753.37

\section{General rights}

Copyright and moral rights for the publications made accessible in the public portal are retained by the authors and/or other copyright owners and it is a condition of accessing publications that users recognise and abide by the legal requirements associated with these rights.

- Users may download and print one copy of any publication from the public portal for the purpose of private study or research.

- You may not further distribute the material or use it for any profit-making activity or commercial gain

- You may freely distribute the URL identifying the publication in the public portal

If you believe that this document breaches copyright please contact us providing details, and we will remove access to the work immediately and investigate your claim 


\title{
Importance of Local Structural Variations on Recrystallization
}

\author{
D. Juul Jensen ${ }^{1, a}$, F.X. Lin ${ }^{1, b}$, Y.B. Zhang ${ }^{1, c}$ and Y.H. Zhang ${ }^{2, d}$ \\ ${ }^{1}$ Materials Science and Advanced Characterization Section, Department of Wind Energy, \\ Technical University of Denmark, Risø Campus, DK-4000 Roskilde, Denmark \\ ${ }^{2}$ Suzhou Institute of Nonferrous Metals Research Co. Ltd., Suzhou, Jiangsu 215026, China

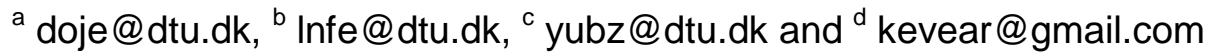

Keywords: protrusions, boundary migration, second phase particles, recrystallization kinetics

\begin{abstract}
Effects of local variations in the deformation microstructure on subsequent recrystallization are discussed and illustrated by three examples. The three examples consider local variations on different length scales and are:

1. Effects of local variations in the deformation microstructure on the formation of protrusions on migrating boundaries.

2. Effects of an inhomogeneous spatial distribution of second phase particles on growth.

3. Effects of stored energy and orientation variations on recrystallization kinetics.
\end{abstract}

\section{Introduction}

Recrystallization is often described by overall sample averaged relations. Examples are JMAK description of recrystallization kinetics [1-3] and the use of the equation

$$
\mathrm{v}=\mathrm{M} \cdot \mathrm{F}
$$

to describe the average boundary migration velocity based on sample averaged measurements of stored energy $\mathrm{F}$ by e.g. calorimetry and generalized assumptions for the mobility $\mathrm{M}$ [e.g. 4]. It is, however, clear that local variations on various length scales are very important for recrystallization. This has been considered extensively for nucleation of recrystallization. It is thus well accepted that potential nucleation sites differ from the surrounding matrix in orientation and/or local stored energy. Classic examples are nucleation at triple junctions [5] and grain boundaries [6], particle stimulated nucleation [7-9] and nucleation at deformation induced "inhomogeneities" such as transition bands [10]. Less work has been devoted to investigations of effects on local structural variations on grain boundary migration during recrystallization and on recrystallization kinetics which are the focal points of this paper.

\section{Effects of local variations in the deformed microstructure}

During the last 25 years detailed investigations of deformation microstructures by advanced experimental techniques have led to a paradigm shift in the way these structures are characterized and analyzed [11]. Now it is well accepted that the structural evolution in both polycrystals and single crystals can be described as a structural subdivision by dislocations and high angle dislocation boundaries forming hierarchical structures on a finer and finer scale as the strain is increased [11-15]. This subdivision leading to variations in the local orientations and stored energies on the micrometer or even sub micrometer scale is of utmost importance for growth during recrystallization. A grain will typically experience large variations in 
misorientation to the deformed matrix along its grain boundary and these misorientation relationships will change in both space and time while the grain is growing [16, 17]. It is therefore often observed that the shapes of the recrystallizing grains in partly recrystallized samples are quite complex and far away from simple spherical or ellipsoidal shapes. Besides this, locally there are often protrusions and retrusions on the boundaries between recrystallizing grains and the deformed matrix, which reflects the local variations in the deformed microstructure.

Sometimes small $\sim 1 \mu \mathrm{m}$ sized pro-/retrusions are observed as ripples on the boundaries but more often larger pro-/retrusions are observed with sizes in the order of tens of micrometers. Generally the shapes of the larger protrusions may be classified into two types: sawtooth shaped and rounded. Two particularly clear examples are shown as sketches in Fig 1. In the case of sawtooth protrusions, it is clear that one of the straight sides runs along an extended dislocation boundary (see Fig 1a). It thus appears that the recrystallizing grain resists growing across this boundary which is a boundary with a significantly higher misorientation angle than a typical cell boundary. In that case the recrystallization boundary may preferentially migrate along the pinning dislocation boundary and therefore into volume elements of the deformed matrix with largely similar orientations as indicated by the arrows in Fig 1a. It is clear that not all dislocation boundaries have this effect. It appears that mostly extended dislocation boundaries with medium to high angle misorientations, which subdivide the original grain into different domains, give rise to the formation of sawtooth protrusions and thus to preferential migration along the dislocation boundaries rather than across them. However further studies are needed to clarify possible angular dependencies.

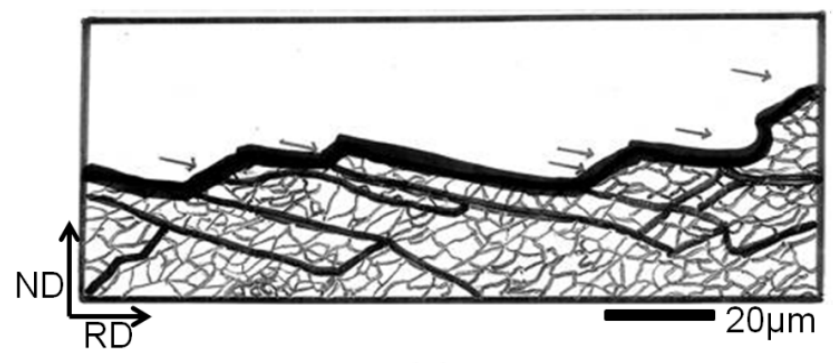

(a)

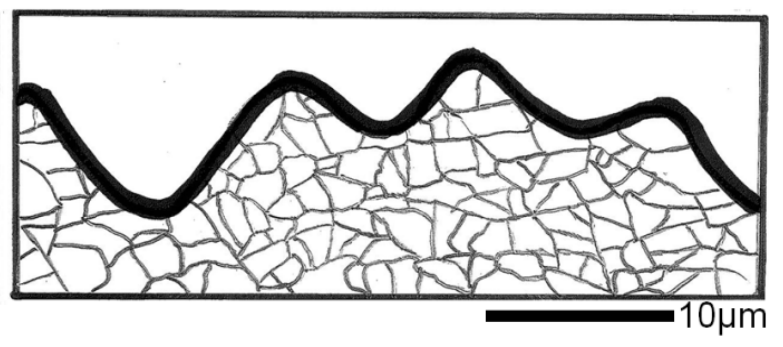

(b)

Fig 1. Sketches of protrusions on recrystallization boundaries in $4 \mathrm{~N}$ pure $\mathrm{Al}$ (cr $50 \%$ and annealed at $250^{\circ} \mathrm{C}$ for $10 \mathrm{~min}$. a) Sketch based on ECC image showing sawtooth shaped protrusion. The fat lines in the deformation microstructure represent extended dislocation boundaries across which a significant contrast variation is observed. The arrows indicate the expected direction of boundary migration. b) Sketch based on a TEM image showing rounded protrusions.

More rounded protrusions are also observed (see Fig 1b), and in many samples they are more frequent than the sawtooth ones. The rounded shape could be a consequence of either more complex (turbulent) or more simple deformation microstructures, e.g. cell structures. Important parameters determining the formation and shape of the protrusions may be the strain and the initial orientation of the grain which is known to determine the "pattern" of subdivision [18]. Misorientation relationships between the growing grain and the various elements in the deformed matrix may also play a role. The rounded shape of many of the protrusions could also be a consequence of the migration itself; because even in the sawtooth case, the recrystallization 
boundary will of course eventually migrate across the pinning dislocation boundary (if the pinning dislocation boundary is not eliminated by growth of another sawtooth protrusion), and the shape of the whole protrusion will appear more rounded.

Retrusions are often a mirror image of the protrusions and in the cases where a boundary is rough with many pro-/retrusions it is hard to define the "neutral" boundary line. However, it appears that some retrusions may be more narrow and sharp than protrusions, which is also predicted by phase field simulations [19], and experimentally larger local curvatures are on average observed at the tip of retrusions than of protrusions [20, 21].

It is clear that the subdivision of the deformation microstructure strongly affects the boundary migration during recrystallization and the formation of pro-/retrusions. According to equation [1], large values for $\mathrm{M}$ and $\mathrm{F}$ will lead to fast migration. High angle dislocation boundaries in the deformed microstructure represent local volumes with high stored energy (F) and one should thus expect a fast migration along these boundaries. This may give rise to the ripples sometimes observed. The larger sawtooth shaped protrusions may however to a large extent be determined by differences in mobility for different segments of the recrystallization boundary meeting deformation microstructures of somewhat different orientations due to the subdivision by medium to high angle dislocation boundaries. Further in-situ or ex-situ experiments are needed to clarify this. Also more focus should be on the 3D shape of the pro-/retrusions, which is needed for a proper characterization and understanding of this effect of local variations in the deformed microstructure on grain boundary migration.

\section{Effects of an inhomogeneous distribution of second phase particles}

It has long been recognized that second-phase particles have significant effects on recrystallization: large particles stimulate nucleation [7-9] and small particles inhibit boundary migration by Zener pinning [22, 23]. Concerning the effect of the large particles some of the more recent work [9] has revealed that the deformation zones around even spherical large second phase particles are inhomogeneously shaped. It was shown that the zones are related not only to particle shape but also the grain orientation. The zones are further influenced by nearby particles [9]. This will clearly affect the nucleation.

If large and small second phase particles are inhomogeneously distributed within the original grains, this will affect not only nucleation but also growth. This was studied by serial sectioning of a material which contained large particles mostly distributed along original grain boundaries as well as round and rod shaped dispersoids inhomogeneously clustered in different zones within the original grains (see Fig 2a). The microstructures in each section were characterized by ECC to identify particles and recrystallizing grains and EBSP to determine the orientations of the grains (see Fig 2b). It was confirmed that the clusters of the large particles are very powerful nucleation sites [24]. Already after a short period of growth, a large size variation of the recrystallizing grains was observed. At this early stage of recrystallization, the size difference does not relate only to the orientations of the grains but is to a large extent determined by the inhomogeneous distribution of the dispersoids. For example, grains within zones with small round dispersoids ( $\mathrm{C}$ in Fig 2a) are on average smaller than those in particle-free zones (A in Fig 2a). This is expected due to pinning effects. However, more surprisingly recrystallizing grains within zones with rod shaped dispersoids are observed to be larger than those in particle-free zones. This has been related to the spatial distribution of the three types of zones (A, B, C in Fig 2a). For a further discussion, see [24]. 3D investigations of this type are rare [24- 26] but are 
considered essential for the further advancement in understanding size/orientation nuclei relationships.

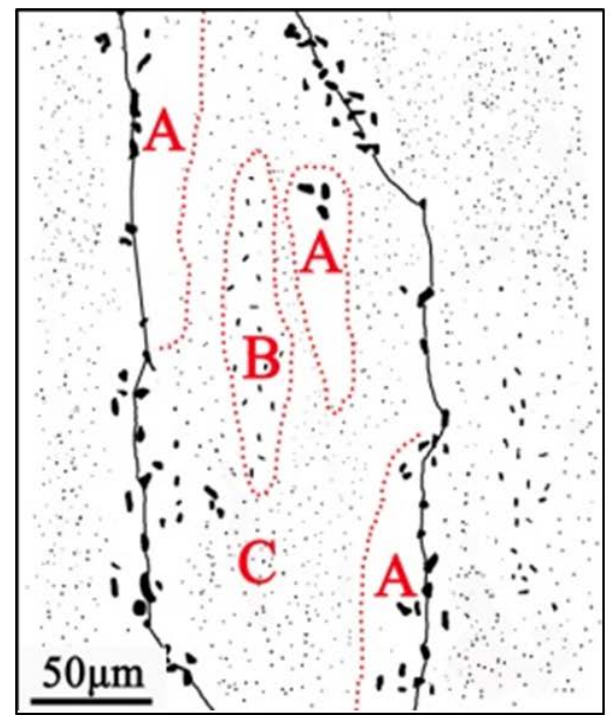

(a)

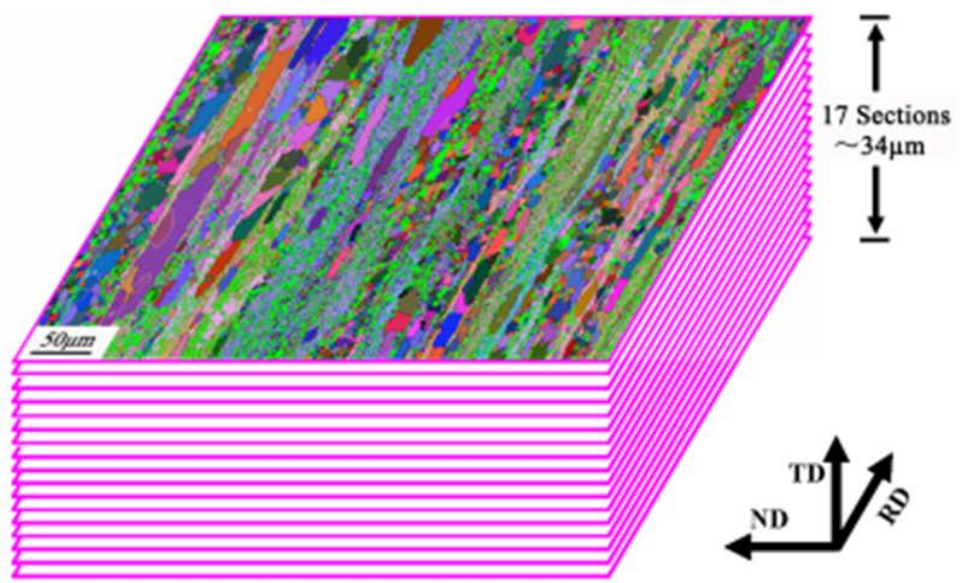

(b)

Fig 2. a) Sketch of distribution of second phase particles in a commercial direct chill-cast AA 3104 aluminium alloy cold rolled 80\%. Large intermetallic particles are seen the original grain boundaries. Particle-free zones are marked by A and zones with rod shaped and round dispersoids are marked by $\mathrm{B}$ and $\mathrm{C}$, respectively. For clarity the dispersoids are drawn larger $(\sim \mathrm{X}$ 4) than their real size [24]. b) Illustration of the inspected sample volume consisting of 17 sections, each approx. $2 \mu \mathrm{m}$ apart. Each RD/ND section is 510 x $340 \mu \mathrm{m}$.

\section{Effects of inhomogeneous distribution of stored energy}

The JMAK model mentioned in the introduction is often found to fit experimental data for recrystallization kinetics well, but still fails, because exponents lower than the expected 3-4 are found. This has been discussed often [e.g. 27]. In a recent work [28] on recrystallization kinetics of copper deformed by dynamic plastic deformation, an exponent as low as 0.56 was found in spite of the recrystallized grains being almost spherical [28]. EBSP investigations of partly recrystallized samples reveal very inhomogeneous recrystallization, where large areas were fully recrystallized while recrystallization had not started in other large areas; see Fig 3a. This macroscale inhomogeneity was related to the heterogeneous distribution stored energies in the deformed sample. A similar idea was suggested by Doherty et al. [29]. In [28] a simple model is suggested, which operates with two recrystallization kinetics, a fast and a slow. If the kinetics difference between the two is big and there is about equal amounts of material following the two types, the overall kinetics for the whole sample is shown to have a large time interval during which the volume fraction of recrystallized material does not change much - i.e. a low JMAK exponent would be measured here, see Fig 3b. It is thus suggested that also macroscale inhomogeneities are considered and, if relevant, included when deriving advanced recrystallization kinetics models. 


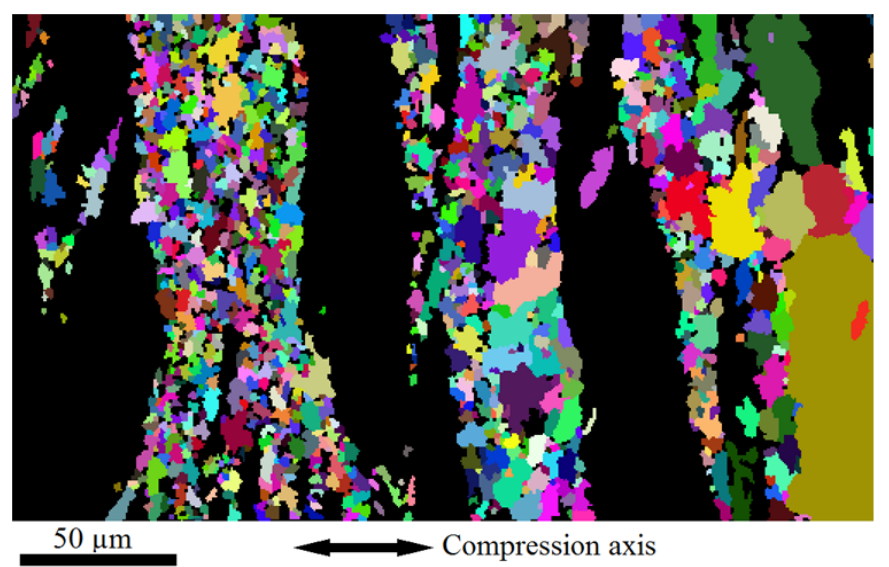

(a)

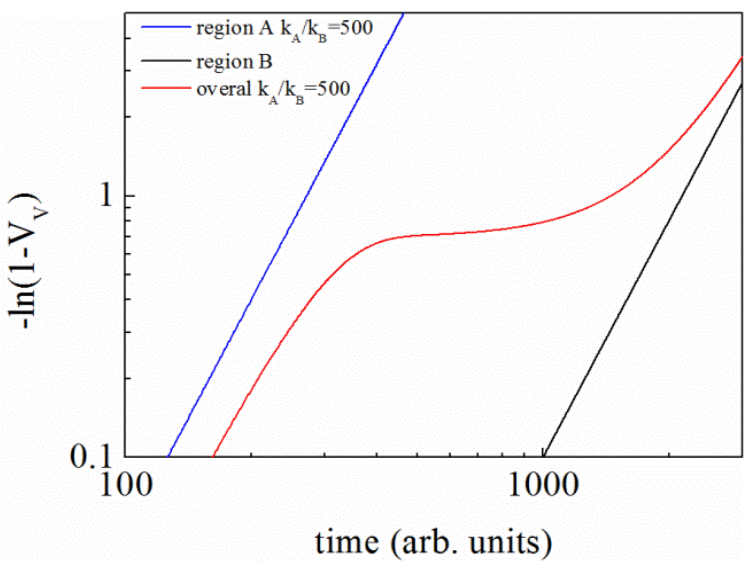

(b)

Fig 3. a) EBSP map of $4 \mathrm{~N}$ pure copper with an initial grain size of $200 \mu \mathrm{m}$ deformed by dynamic plastic deformation in 17 impacts to a strain of 2 followed by annealing for $1 \mathrm{~h}$ at $120^{\circ} \mathrm{C}$ to partial recrystallization. For clarity the recrystallized grains are highlighted in random colours and the still deformed areas are shown in black [28]. b) Theoretical kinetics curves assuming two distinct recrystallization kinetics processes - a fast and a slow one (differing by a factor of 500 in $\mathrm{k}$; where $\mathrm{V}_{\mathrm{v}}=1-\exp \left(-\mathrm{kt}^{3}\right)$ for each region) and assuming equal volumes of the two regions. The red curve shows the overall kinetics, whereas the two straight lines show the kinetics in the two regions.

\section{Concluding remarks}

After plastic deformation, the microstructure is typically inhomogeneous with local variations in crystallographic orientation and stored energy (see also [30]). Besides this, also parameters like distribution of second phase particles and deformation mode can give rise to heterogeneities. It has been shown that both the local variations and the more macroscopic heterogeneities strongly affect boundary migration during recrystallization. It is thus suggested that local microstructural variations and other heterogeneities are considered when the goal is to understand the recrystallization mechanisms and that recrystallization can be used to give fingerprint of inhomogenieties in deformation microstructures and thus complement studies hereof.

\section{Acknowledgements}

The authors gratefully acknowledge the support from the Danish National Research Foundation and the National Natural Science Foundation of China (Grant No. 51261130091) to the Danish-Chinese Center for Nanometals, within which this work has been performed.

\section{References}

[1] M. Avrami, J. Chen. Phys. 7 (1939) 1103-1112.

[2] W.A. Johnson and R.F. Mehl, Trans AIME 135 (1939) 416-458.

[3] A.N. Kolmogorov, Izv, Akad. Nauk, USSR-sev. Matemat 1 (1937) 355-359. 
[4] Y. Huang and F.J. Humphreys, Acta Mater. 48 (2000) 2017-2030.

[5] R.A. Vandermeer and P. Gordon, Trans. AIME 215 (1959) 577-588.

[6] P.A. Beck and P.R. Sperry, J. Appl. Phys. 21 (1950) 150-152.

[7] W.C. Leslie, J.T. Michalak and F.W. Aul, Eds. Spencer and Werner Interscience NY (1963) 119-216.

[8] F.J. Humphreys, Acta Metall. Mater. 15 (1977) 1323-1344.

[9] F.J. Humphreys, P. Bate, A. Gholinia and I. Brough, Mat. Sci. Forum 715-716 (2012) 23-32.

[10] S.P. Bellier and R.D. Doherty, Acta Mat. 25 (1977) 521-538.

[11] N. Hansen and D. Juul Jensen, Mat. Sci. and Tech. 27 (2011) 1229-1240.

[12] N. Hansen and D. Kuhlmann-Wilsdorf, Mater. Sci. Eng. 81 (1986) 141-161.

[13] J.H. Driver, D. Juul Jensen and N. Hansen, Acta Metall. et Mater. 42 (1994) 3105-3114.

[14] A. Godfrey, D. Juul Jensen and N. Hansen, Acta Mater. 49 (2001) 2429-2440.

[15] M. Ferry, W.Q. Xu, M.Z. Quadir, N.A. Zinnia, K.J. Laws, N. Mateescu, L. Robin, L. Bassman, J.M. Cairney, J.F. Humphreys, A. Albou and J.H. Driver, Mat. Sci. Forum 715-716 (2012) 41-50.

[16] E.M. Lauridsen, H.F. Poulsen, S.F. Nielsen and D. Juul Jensen, Acta Mater. (2003) 44234435.

[17] S.O. Poulsen, E.M. Lauridsen, A. Lyckegaard, J. Oddershede, C. Gundlach, C. Curfs and D. Juul Jensen, Scripta Mater. 64 (2011) 1003-1006.

[18] X. Huang and G. Winther, Phil. Mag. 87 (2007) 5189-5214.

[19] N. Moelans, to be submitted for publication.

[20] Y.B. Zhang, A. Godfrey, D. Juul Jensen, Comput., Mater. \& Continua 14 (2009) 197-207.

[21] Y.B. Zhang, A. Godfrey, D. Juul Jensen, Scripta Mater. 64 (2011) 331-334.

[22] N. Hansen and B. Bay, Acta Metall. 29 (1981) 65-77.

[23] C.S. Smith, Metal. Soc. AIME 175 (1948) 15-51.

[24] Y.H. Zhang, D. Juul Jensen, Y.B. Zhang, F.X. Lin, Z. Zhang and Q. Liu, Scripta Mater. 67 (2012) 320-323.

[25] J. Konrad, Z. Zaefferer and D. Raabe, Acta Mater. 54 (2006) 1369-1380.

[26] H. Weiland, T.N. Rouns and J. Liu, Z Metallkd. 85 (1994) 592-597.

[27] R.A. Vandermeer, Proc. 16th Risø Int. Symp. on Mat. Sci. Eds N. Hansen, D. Juul Jensen, Y.L. Liu and B. Ralph, Risø Denmark (1995) 193-213.

[28] F.X. Lin, Y.B. Zhang, W. Pantleon and D. Juul Jensen, Proc. $33^{\text {rd }}$ Risø Int. Symp. on Mat. Sci. Eds. S. Fæster, N. Hansen, X. Huang, D. Juul Jensen and B. Ralph, Risø Denmark (2012) 217-222.

[29] R.D. Doherty, A.R. Rollett and D.J. Srolovitz, Proc. $7^{\text {th }}$ Risø Int. Symp. on Mat. Sci. Eds. N. Hansen et al., Risø Denmark (1986) 53-67.

[30] N. Hansen, T.B. Yu, O.V. Mishing and X. Huang, these proceedings. 